\title{
Klebsiella singaporensis sp. nov., a novel isomaltulose-producing bacterium
}

Correspondence

Xianzhen Li

xianzhen@mail.com

\author{
Xianzhen Li, ${ }^{1}$ Daohai Zhang, ${ }^{2}$ Feng Chen, ${ }^{3}$ Jie Ma, ${ }^{1}$ Yihu Dong ${ }^{2}$ \\ and Lianhui Zhang ${ }^{2}$ \\ ${ }^{1}$ Department of Bio and Food Engineering, Dalian College of Light Industry, Dalian 116034, \\ PR China \\ ${ }^{2}$ IMA, National University of Singapore, Singapore 117612 \\ ${ }^{3}$ Department of Botany, Hong Kong University, Hong Kong, PR China
}

Isomaltulose (6-O- $\alpha$-D-glucopyranosyl-D-fructofuranose), a functional isomer of sucrose, is a non-cariogenic reducing disaccharide found naturally in small quantities in honey. It has physical and organoleptic properties very similar to those of sucrose, except that its sweetness is about $42 \%$ that of sucrose. Isomaltulose is decomposed only slightly by Streptococcus mutans and by dental plaque suspensions. Much less acid and insoluble glucan are produced from isomaltulose compared with that from sucrose in human dental plaque (Takazoe et al., 1982; Topitsoglou et al., 1984). Since isomaltulose was first reported by Stodola et al. (1956) as a by-product during dextran production from sucrose, microbial transformation of sucrose to isomaltulose has been reported for several bacteria such as 'Protaminobacter rubrum' (Weidenhageen \& Lorenz, 1957), Erwinia rhapontici (Cheetham et al., 1982), Serratia plymuthica (McAllister et al., 1990), Klebsiella planticola (Tsuyuki et al., 1992) and 'Pseudomonas mesoacidophila' (Miyata et al., 1992). However, these isomaltulose-producing strains not only transform sucrose to isomaltulose and trehalulose, but also

The GenBank/EMBL/DDBJ accession numbers for the 16S rRNA gene and $r p o B$ nucleotide sequences of strain $L X 3^{\top}$ are respectively AF250285 and AF250286. produce about $2-7 \%$ glucose as by-products (Tsuyuki et al., 1992), which is a considerable industrial problem because elaborate purification is necessary to remove them. In our efforts to screen for efficient isomaltulose-producing bacterial strains, one isolate, designated $\mathrm{LX}^{\mathrm{T}}{ }^{\mathrm{T}}$, was obtained from soil samples. This strain produced isomaltulose efficiently but glucose was not detectable.

The latest edition of Bergey's Manual of Systematic Bacterio$\operatorname{logy}$ (Ørskov, 1984) classified the genus Klebsiella into four species, Klebsiella pneumoniae, Klebsiella oxytoca, Klebsiella terrigena and $K$. planticola, with $K$. pneumoniae comprising three subspecies, K. pneumoniae subsp. pneumoniae, K. pneumoniae subsp. ozaenae and K. pneumoniae subsp. rhinoscleromatis. Klebsiella ornithinolytica was subsequently described for ornithine-positive strains of $K$. oxytoca (Sakazaki et al., 1989). Klebsiella trevisanii has been incorporated into $K$. planticola as a later heterotypic synonym, and Klebsiella mobilis is a later homotypic synonym of Enterobacter aerogenes. Calymmatobacterium granulomatis was reclassified as Klebsiella granulomatis on the basis of phylogenetic data (Carter et al., 1999). The genus Klebsiella is polyphyletic and has not been subjected to extensive $16 \mathrm{~S}$ rRNA gene sequence analysis until recently. After phylogenetic analysis of $16 \mathrm{~S}$ rRNA and $r p o B$ gene 
sequences, Drancourt et al. (2001) confirmed that the genus Klebsiella is heterogeneous and composed of species that form three clusters: cluster I, containing $K$. granulomatis and the three subspecies of $K$. pneumoniae; cluster II, containing $K$. ornithinolytica, $K$. planticola and $K$. terrigena; and cluster III, containing K. oxytoca. The genus Klebsiella was therefore divided into two genera, Klebsiella and Raoultella, and an unnamed genogroup.

In this paper, the results of an examination of the phenotypic characteristics of strain $\mathrm{LX}^{\mathrm{T}}$ are described, along with the phylogenetic placement of the strain. The name Klebsiella singaporensis sp. nov. is proposed with strain $\mathrm{LX}^{\mathrm{T}}$ as the type strain.

Soil samples were suspended in sterilized saline water and spread over sucrose agar plates in serial dilution. All plates were incubated at $30^{\circ} \mathrm{C}$ for $24 \mathrm{~h}$. A part of each single colony on the sucrose agar plate was transferred to a new sucrose agar plate as a temporary stock culture. Another part was inoculated into sucrose/peptone/yeast extract (SPY) medium and incubated at $30^{\circ} \mathrm{C}$ with shaking overnight. This culture was used to detect strains producing isomaltulose, by the dinitrosalicylate method (Miller, 1959) and TLC. Sucrose agar medium contained (per $1000 \mathrm{ml}$ ) $40 \mathrm{~g}$ sucrose, $5 \mathrm{~g}$ yeast extract, $0.5 \mathrm{~g}$ $\mathrm{MgSO}_{4} \cdot \mathrm{H}_{2} \mathrm{O}, 0.7 \mathrm{~g} \mathrm{KNO}_{3}, 1 \mathrm{~g} \mathrm{~K}_{2} \mathrm{HPO}_{4}, 0.5 \mathrm{~g} \mathrm{NH}_{4} \mathrm{Cl}$, $1 \mathrm{~g} \mathrm{NaCl}$ and $20 \mathrm{~g}$ agar; the $\mathrm{pH}$ was adjusted to $7 \cdot 0$ with $\mathrm{NaOH}$. SPY medium comprised (per $1000 \mathrm{ml}) 40 \mathrm{~g}$ sucrose, $10 \mathrm{~g}$ peptone and $4 \mathrm{~g}$ yeast extract $(\mathrm{pH} 7 \cdot 0)$. Basal medium consists of (per $1000 \mathrm{ml}$ ) $0.5 \mathrm{~g} \mathrm{MgSO}_{4} \cdot \mathrm{H}_{2} \mathrm{O}$, $0.7 \mathrm{~g} \mathrm{KNO}_{3}, 1 \mathrm{~g} \mathrm{~K}_{2} \mathrm{HPO}_{4}, 0.5 \mathrm{~g} \mathrm{NH}_{4} \mathrm{Cl}$ and $1 \mathrm{~g} \mathrm{NaCl}$ $(\mathrm{pH} 7 \cdot 0-7 \cdot 2)$.

With this method, single colonies producing isomaltulose from sucrose were isolated from soil samples collected from sugar-cane roots and Clementi Woods in Singapore. The isolate was purified further on the sucrose agar plate by streaking; the purified strain was designed as $\mathrm{LX}^{\mathrm{T}}{ }^{\mathrm{T}}$.

The reference strains used in DNA reassociation studies were K. pneumoniae subsp. pneumoniae ATCC $13883^{\mathrm{T}}, K$. pneumoniae subsp. ozaenae ATCC $11296^{\mathrm{T}}$, K. pneumoniae subsp. rhinoscleromatis ATCC $13884^{\mathrm{T}}$, K. terrigena ATCC $33257^{\mathrm{T}}$, K. planticola ATCC $33531^{\mathrm{T}}$, K. trevisanii ATCC $33558^{\mathrm{T}}, K$. ornithinolytica ATCC $31898^{\mathrm{T}}$, K. oxytoca ATCC $13182^{\mathrm{T}}$ and K. mobilis (= Enterobacter aerogenes) ATCC $13048^{\mathrm{T}}$.

A $0.5 \mu \mathrm{l}$ aliquot of the culture supernatant, in which reducing sugar could be detected by the dinitrosalicylate method (Miller, 1959), was spotted onto a TLC plate (silica gel on polyester; Aldrich) and developed. The solvent system was ethylacetate/acetic acid/water $(4: 3: 0 \cdot 8$ by vol.). The spots were visualized with the diphenylamine/ aniline/phosphoric acid reagent (Schwimmer \& Bevenue, 1956) at $80^{\circ} \mathrm{C}$ for $5 \mathrm{~min}$. The spot colour of isomaltulose is yellowish-green. If the spot that occurred was of the same colour, and in the same position, as that of an isomaltulose standard sample on the silica-gel plate, it demonstrated that the strain could produce isomaltulose.

Unless otherwise indicated, all experiments were conducted in triplicate.

The cultures were grown on sucrose agar for $16 \mathrm{~h}$ at $30^{\circ} \mathrm{C}$ and bacterial cells were examined with a phase-contrast microscope and a transmission electron microscope. For transmission microscopy, bacterial cells were fixed with $5 \%$ $(\mathrm{w} / \mathrm{v})$ glutaraldehyde and $1 \%(\mathrm{w} / \mathrm{v})$ osmium tetroxide. Ultrathin sections of the sample embedded in epoxy resin were prepared with an ultramicrotome (Leica Microsystems), stained with uranyl acetate and lead citrate and then examined with a model JEM-1200 EX transmission electron microscope (Japan Electron Optics Laboratory). Cellular morphology was also assessed after Gram staining and was observed by light microscopy; the morphology of fixed specimens was compared with that of living cells. Gram-staining characteristics were determined using the Hucker method, as described by Doetsch (1981).

Oxidase activity was determined by oxidation of $1 \%(\mathrm{w} / \mathrm{v})$ tetramethyl-p-phenylenediamine on filter paper, and catalase activity was detected by bubble formation in a $3 \%$ $(\mathrm{w} / \mathrm{v})$ hydrogen peroxide solution after incubation in SPY medium for 18-48 h (Smibert \& Krieg, 1994). The media used to evaluate utilization of various substrates for growth were prepared by adding $0.2 \%(\mathrm{w} / \mathrm{v})$ of each substrate to a basal medium. In tests of the utilization of carbon sources or nitrogen sources, the optical density at $600 \mathrm{~nm}$ of a culture after cultivation in each medium was compared with the optical density of a culture grown in basal medium. Tests for gelatin hydrolysis, indole production, hydrogen sulphide production, nitrate reduction, acid-fast staining, the Voges-Proskauer reaction, the methyl red reaction and the hydrolysis of starch, casein and agar were performed by using methods described previously (Smibert \& Krieg, 1994). Acid production from carbohydrates was determined in basal medium supplemented with various carbohydrates as described by Smibert \& Krieg (1994).

Growth at different temperatures between 5 and $60{ }^{\circ} \mathrm{C}$ was measured by inoculating a loopful of young culture onto sucrose agar and incubating the inoculated plates at the required temperatures. The growth results were observed at 2 and 10 days.

DNA was extracted from cells grown at $30^{\circ} \mathrm{C}$ overnight in SPY medium, and purified by using the methods described (Wilson, 1990). The G+C content of DNA was determined by the thermal denaturation method described by Marmur \& Doty (1962). Levels of DNA relatedness were determined (hybridization at $64^{\circ} \mathrm{C}$ ) by using the non-radioactive detection system developed by Ziemke et al. (1998).

A $16 \mathrm{~S}$ rRNA gene DNA fragment from strain $\mathrm{LX}^{\mathrm{T}}$ that corresponds to position 95-1395 of Escherichia coli 16S 
rRNA was amplified by a PCR, using purified DNA and a primer combination consisting of 5'-TGACGAGTGGCGGACGGGTG-3' (forward primer) and 5' -CCATGGTGTGACGGGCGGTGTG-3' (reverse primer). The amplification products were purified with a QIAquick PCR purification kit (Qiagen) and were sequenced using a dRhodamine terminator cycle sequencing kit (PE Applied Biosystems) and a model 2400 Perkin Elmer GeneAmp PCR System (PE Applied Biosystems). Sequences were determined with a Perkin Elmer ABI PRISM 377 DNA sequencer. The closest known relatives of the new isolate was determined by performing sequence database searches; the sequences of closely related strains were retrieved from the GenBank and Ribosomal Database Project (Cole et al., 2003) libraries. These sequences were aligned using the CLUSTAL X program (Thompson et al., 1997) and the alignment was corrected manually. Distance matrices were calculated with the DNADIST program of the PHYLIP package (Felsenstein, 1995) and a phylogenetic unrooted tree was constructed with the neighbour-jointing method using the NEIGHBOR program contained in the PHYLIP package (Felsenstein, 1995). The statistical significance of the groups obtained was assessed by bootstrapping (100 replicates) using the programs SEQBOOT, DNADIST, NEIGHBOR and CONSENSE in the PHYLIP package (Felsenstein, 1995).

The genomic DNA of strain $\mathrm{LX} 3^{\mathrm{T}}$ encoding the RNA polymerase $\beta$-subunit $(r p o B)$ gene, corresponding to positions 1468-2114 of Escherichia coli rpoB, was amplified by a PCR using primers designed with reference to the consensus regions of the published sequences for Escherichia coli (GenBank accession no. V00340), Salmonella typhimurium (X04642), Pseudomonas putida (X15849) and K. pneumoniae (U77443): 5'-CAGTTCCGCGTTGGCCTG-3' (forward primer) and $5^{\prime}$-CGGTTGGCGTCATCGTGTTC-3' (reverse primer). The PCR products were purified and sequenced as described above. The phylogenetic analysis of $r p o B$ was carried out using the same procedure and program as that for $16 \mathrm{~S}$ rRNA.

Colonies on sucrose agar medium were circular, smooth, pulvinate, entire, opaque, white and viscous when tested with a needle. Strain $\mathrm{LX} 3^{\mathrm{T}}$ comprised Gram-negative, nonmotile, straight rods with round ends, arranged singly and sometimes in pairs. The mean cell dimensions on sucrose agar medium were $0 \cdot 6-0 \cdot 8 \mu \mathrm{m}$ (diameter) and $0 \cdot 9-2 \cdot 0 \mu \mathrm{m}$ (length). Endospores were never observed.

Strain $\mathrm{LX} 3^{\mathrm{T}}$ exhibited catalase and urease activities, but not oxidase, nitrate reductase or lipase activities. It failed to hydrolyse gelatin, starch, cellulose or casein. The VogesProskauer test was positive but the methyl red reaction was negative. $\mathrm{LX}^{\mathrm{T}}$ was facultatively anaerobic and capsulated. The isolate grew when citrate or glucose was used as a sole carbon source. It produced acid and gas from the carbon sources tested, including glucose, sucrose, lactose, trehalulose, maltose, fructose, mannitol, glycerol, inositol, mannose, galactose and sorbitol. It could not utilize palatinose or L-sorbose as sole carbon sources. Nitrogen sources such as peptone, tryptone, yeast extract, beef extract, casein hydrolysate, $\mathrm{KNO}_{3}$ and $\left(\mathrm{NH}_{4}\right)_{2} \mathrm{SO}_{4}$ supported growth of the isolate, whereas urea did not. The isolate had no special growth-factor requirements. $\mathrm{H}_{2} \mathrm{~S}$ was produced from cysteine but not from triple-sugar-iron agar. The test for indole production was positive. The isolate could grow at $10^{\circ} \mathrm{C}$ but could not produce gas from lactose at $45^{\circ} \mathrm{C}$.

According to the previous description of the genus Klebsiella (Ørskov, 1984), this genus has the following morphological characteristics: a negative reaction in Gram-stain and oxidase tests, is facultatively anaerobic, rod-shaped and nonmotile, gives a positive reaction in the Voges-Proskauer test, and produces capsules. These characteristics were consistent with those of our isolate, suggesting that strain $\mathrm{LX}^{\mathrm{T}}$ should belong to the genus Klebsiella.

The G $+\mathrm{C}$ content of strain $\mathrm{LX}^{\mathrm{T}}$ was $56 \cdot 4 \pm 0 \cdot 7 \mathrm{~mol} \%$, which was comparable to that of the genus Klebsiella (53-58 mol\%). The DNA-DNA relatedness between the newly isolated strain and Klebsiella species ranged from $3 \cdot 4$ to $28 \cdot 2 \%$. Strain $\mathrm{LX}^{\mathrm{T}}$ exhibited $16 \cdot 7-28 \cdot 2 \%$ relatedness with members of Klebsiella cluster I, except for K. pneumoniae subsp. rhinoscleromatis, for which the value was lower $(3 \cdot 4 \%)$. Klebsiella cluster II containing K. planticola, $K$. trevisanii, $K$. ornithinolytica and $K$. terrigena exhibited values of $12 \cdot 3-25 \cdot 5 \%$ for relatedness to isolate $\mathrm{LX}^{\mathrm{T}}$. With $K$. oxytoca and $K$. mobilis (=Enterobacter aerogenes), strain $\mathrm{LX} 3^{\mathrm{T}}$ showed $15 \cdot 5-20 \cdot 5 \%$ DNA-DNA relatedness. Although the values of DNA-DNA relatedness were below the threshold value of $28 \%$ recommended for genus delineation in the Enterobacteriaceae, these values were in the range of those previously reported in the analysis of the genus Klebsiella. Values as low as $13-38 \%$ for $K$. ornithinolytica to $K$. planticola and $10-34 \%$ to $K$. terrigena (Sakazaki et al., 1989) and 7-29\% relatedness of K. planticola and K. pneumoniae (Bagley et al., 1981) have been cited in previous phylogenetic analyses of the genus Klebsiella, and numerous bacterial species in other genera also exhibited much lower DNA-DNA relatedness (Etchebehere et al., 1998; Yoon et al., 2001). Likewise, the low DNA-DNA relatedness with the members of the genus Klebsiella clearly supported the classification of the isolate in a novel species of the genus Klebsiella.

The 16S rRNA gene sequence of strain $\mathrm{LX}^{\mathrm{T}}$ was determined using a total of eight primers for double-strand sequencing; a 1282-base sequence was obtained. Comparison with 16S rRNA gene sequences available in databases revealed that strain $\mathrm{LX}^{\mathrm{T}}$ was closely related to species belonging to the genus Klebsiella and was peripherally related to some species of the genera Enterobacter and Citrobacter. The most closely related species was $K$. pneumoniae and the levels of sequence similarity among strains tested ranged from $97 \cdot 2$ to $99 \cdot 3 \%$. The dataset used for the construction of the phylogenetic tree contained 1281 unambiguous nucleotides between positions 95 and 1395 (Escherichia coli position numbers). A dendrogram 


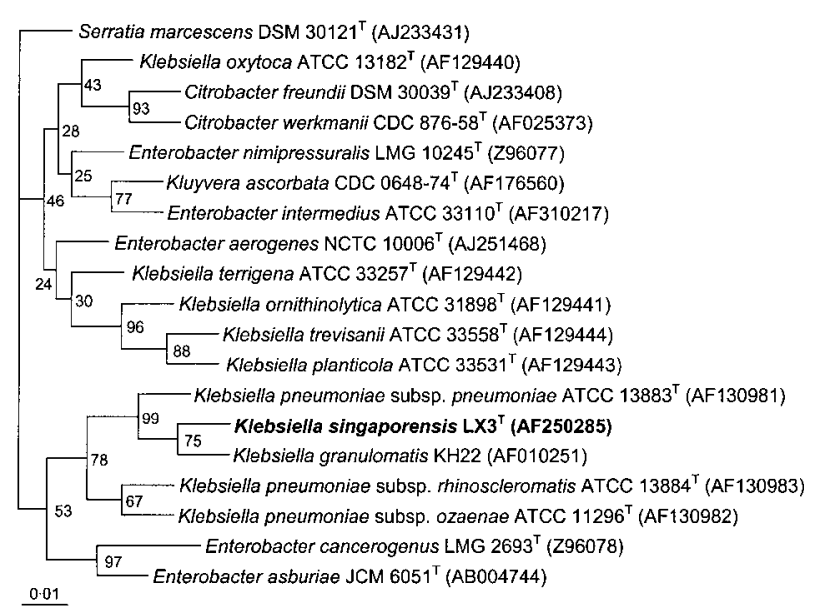

Fig. 1. Phylogenetic tree derived from 16S rRNA gene sequence analysis, showing the position of $K$. singaporensis sp. nov. among related members of the Enterobacteriaceae. The tree was generated by the neighbour-joining method. Bootstrap percentages are given at the nodes. Serratia marcescens was used as an outgroup. GenBank accession numbers are given in parentheses. Bar, $1 \%$ sequence divergence.

generated by the neighbour-joining method is shown in Fig. 1.

Recently Drancourt et al. (2001) divided the genus Klebsiella into three clusters, which grouped K. granulomatis and the three subspecies of K. pneumoniae into cluster I as Klebsiella sensu stricto, grouped $K$. planticola, K. terrigena and $K$. ornithinolytica into cluster II, given the new genus name Raoultella, and grouped K. oxytoca in cluster III. It was evident from tree topology that strain $\mathrm{LX} 3^{\mathrm{T}}$ had a close phylogenetic relationship with members of cluster I (i.e. Klebsiella sensu stricto). These data demonstrated that strain $\mathrm{LX}^{\mathrm{T}}$ clearly belongs to the genus Klebsiella and that the closest relative is K. pneumoniae (99.3\% similarity). This relationship between the cluster of strain $\mathrm{LX}^{\mathrm{T}}$, $K$. pneumoniae and K. granulomatis was supported by the bootstrap analysis at a confidence level of $99 \%$. Strain $\mathrm{LX}^{\mathrm{T}}$ exhibited $98 \cdot 6-98 \cdot 8 \%$ 16S rRNA gene sequence similarity to the other three species in Klebsiella cluster I, $97 \cdot 6-97 \cdot 7 \%$ similarity to Klebsiella cluster II and $97 \cdot 2 \%$ sequence similarity to K. oxytoca. With other related species in the genera Enterobacter or Citrobacter, however, the $16 \mathrm{~S}$ rRNA sequence similarities ranged from $97 \cdot 2$ to $97 \cdot 9 \%$. It was obvious that strain $\mathrm{LX}^{\mathrm{T}}$ and cluster I shared a higher similarity than did strain $\mathrm{LX}^{\mathrm{T}}$ and cluster II or III. These data were in accordance with the proposal of $98 \% 16 \mathrm{~S}$ rRNA gene sequence similarity as a cut-off value for delineating different genera (Drancourt et al., 2001). Also, such a differentiation at genus level was further supported by biochemical characteristics, as only cluster II and cluster III could utilize L-sorbose as a sole carbon source. Although strain $\mathrm{LX}^{\mathrm{T}}$ and $\mathrm{K}$. pneumoniae had high $16 \mathrm{~S}$ rRNA gene sequence similarity $(99 \cdot 3 \%)$, the separation of strain $\mathrm{LX}^{\mathrm{T}}$ from the subspecies of $K$. pneumoniae was supported by the low values for DNA-DNA reassociation.

It was noted that in some taxa, particularly members of the Enterobacteriaceae, variation within the 16S rRNA gene prevented confident species identification. Mollet et al. (1997) found that levels of divergence between $r p o B$ sequences (which represented the most variable part of the gene) of different strains in the family Enterobacteriaceae were markedly higher than those between 16S rRNA genes. Thus $r p o B$ gene analysis is another useful identification tool, at least for the species in the Enterobacteriaceae. The partial $r p o B$ gene of strain $\mathrm{LX}^{\mathrm{T}}$ was sequenced to determine its phylogenetic position among the enteric members of the Enterobacteriaceae. The tree topology for $r p o B$ gene sequences was generated as shown in Fig. 2. The $r p o B$ gene sequence of strain $\mathrm{LX} 3^{\mathrm{T}}$ was compared with those of members of the family Enterobacteriaceae available in databases, and a similarity matrix was obtained. In accordance with the inference by Mollet et al. (1997), the highest level of $r p o B$ sequence similarity, between strain $\mathrm{LX}^{\mathrm{T}}$ and K. pneumoniae (97.5\%), was about $2 \%$ lower than that in $16 \mathrm{~S}$ rRNA gene sequence analysis. Accordingly, 98-100\% intraspecies similarity was observed among enteric strains, whereas 2-21.9\% interspecies difference occurred (Mollet et al., 1997). Phylogenetic analysis showed that the smallest divergence is $2.5 \%$ ( $K$. pneumoniae), suggesting that strain $\mathrm{LX}^{\mathrm{T}}$ could be distinguished from other Klebsiella species more confidently. As shown in Fig. 2 (which shows a phylogenetic branching pattern similar to that for the $16 \mathrm{~S}$ rRNA gene), strain $\mathrm{LX}^{\mathrm{T}}$ also fell within Klebsiella cluster I. The most closely related member was $K$. pneumoniae ( $97.5 \%$ similarity), which was supported by an $81 \%$

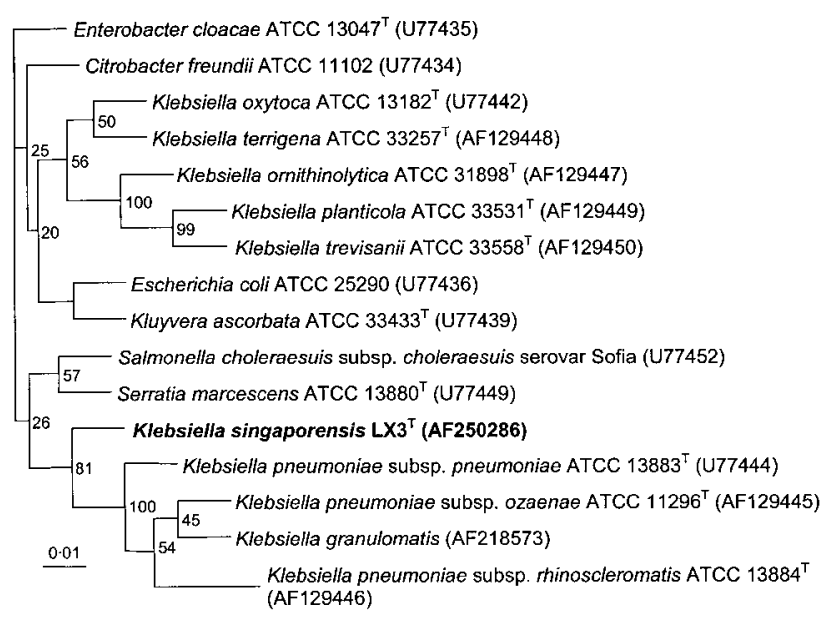

Fig. 2. Phylogenetic tree showing the relationship between $K$. singaporensis sp. nov. and related members of the Enterobacteriaceae based on partial rpo $B$ gene sequences. The tree was generated by the neighbour-joining method. Bootstrap percentages are given at the nodes. Enterobacter cloacae was used as an outgroup. GenBank accession numbers are given in parentheses. Bar, $1 \%$ sequence divergence. 
bootstrap value. Compared with other members of Klebsiella cluster I, strain $\mathrm{LX}^{\mathrm{T}}$ showed $96 \cdot 9-97 \cdot 3 \%$ rpoB gene sequence similarity. Strain $\mathrm{LX}^{\mathrm{T}}$ exhibited low values of sequence similarity $(92 \cdot 4-93 \cdot 4 \%)$ with cluster II and $93.4 \%$ sequence similarity to cluster III. These data were also in good agreement with the proposal of $94 \%$ as the cut-off value for delineating different genera (Drancourt et al., 2001).

The phenotypic characteristics of strain $\mathrm{LX}^{\mathrm{T}}$ were also consistent with its classification in the genus Klebsiella, but there were some notable phenotypic traits that might be very important for distinguishing strain $\mathrm{LX} 3^{\mathrm{T}}$ from other members of Klebsiella: these included indole production, growth at $10^{\circ} \mathrm{C}$, the faecal coliform test and the VogesProskauer test (Table 1). The differences between the isolate and the most closely related species, K. pneumoniae, were that the latter produced gas from lactose at $44 \cdot 5^{\circ} \mathrm{C}$ but failed to grow at $10^{\circ} \mathrm{C}$. Among the differential phenotypic characteristics, strain $\mathrm{LX}^{\mathrm{T}}$ could be distinguished from Klebsiella cluster II or cluster III including K. terrigena by tests for the utilization of palatinose or L-sorbose as sole carbon sources, strain $\mathrm{LX}^{\mathrm{T}}$ being negative and the latter being positive. The problem in evaluating the phylogenetic position of $K$. granulomatis was the difficulty in culturing the organism (Richens, 1991): although a difference in the urease test occurred between strain $\mathrm{LX}^{\mathrm{T}}$ and $K$. granulomatis (urease-negative), the latter usually needed growth factors (Carter et al., 1999) while strain $\mathrm{LX}^{\mathrm{T}}$ does not. To distinguish strain $\mathrm{LX} 3^{\mathrm{T}}$ from $K$. mobilis, the urease test may be decisive; strain $\mathrm{LX}^{\mathrm{T}}$ is urease-positive and $K$. mobilis is urease-negative. The level of DNA-DNA relatedness revealed that strain $\mathrm{LX}_{3}{ }^{\mathrm{T}}$ was distinct from other members of genus Klebsiella.

Table 1. Differential phenotypic characteristics of strain $\mathrm{LX}^{\top}$ and Klebsiella species

Taxa: 1, K. pneumoniae subsp. pneumoniae; 2, K. pneumoniae subsp. rhinoscleromatis; $3, K$. pneumoniae subsp. ozaenae; $4, K$. oxytoca; 5 , K. planticola; 6 , K. ornithinolytica; 7, K. terrigena; $8, \mathrm{~K}$. mobilis (=Enterobacter aerogenes). Results: + , positive; - , negative; ND, not determined.

\begin{tabular}{|c|c|c|c|c|c|c|c|c|c|}
\hline Characteristic & $\mathrm{LX3}^{\mathrm{T}}$ & 1 & 2 & 3 & 4 & $5^{\star}$ & 6 & 7 & 8 \\
\hline Indole production & - & - & - & - & + & + & + & - & - \\
\hline $\begin{array}{l}\text { Gas production from lactose } \\
\text { at } 44 \cdot 5{ }^{\circ} \mathrm{C}\end{array}$ & - & + & + & + & - & - & - & - & + \\
\hline Growth at $10^{\circ} \mathrm{C}$ & + & - & - & - & + & + & + & + & ND \\
\hline Methyl red reaction & - & - & + & + & - & ND & ND & + & ND \\
\hline Voges-Proskauer test & + & + & - & - & + & + & ND & + & + \\
\hline \multicolumn{10}{|l|}{ Utilization of: } \\
\hline Palatinose & - & + & - & - & + & + & + & + & ND \\
\hline L-Sorbose & - & - & - & - & + & + & + & + & + \\
\hline Urease & + & + & - & - & + & + & & + & - \\
\hline
\end{tabular}

${ }^{\star}$ Including $K$. trevisanii isolate.
On the basis of the physiological and phylogenetic characteristics of strain $\mathrm{LX}^{\mathrm{T}}$, as well as DNA-DNA relatedness analyses, it was evident that the isomaltulose-producing strain isolated from soil samples cannot be assigned to any previously recognized bacterial species. We propose that strain $\mathrm{LX} 3^{\mathrm{T}}$ should be placed in a novel species, Klebsiella singaporensis sp. nov.

\section{Description of Klebsiella singaporensis sp. nov.}

Klebsiella singaporensis (sin.ga.po.ren'sis. N.L. fem. adj. singaporensis of Singapore, the country in which the type strain was isolated).

Gram-negative, facultatively anaerobic, straight rods with rounded ends. Non-motile and capsulated. Not endosporeforming. Cells are $0 \cdot 6-0 \cdot 8 \mu \mathrm{m}$ in diameter and $0 \cdot 9-2 \cdot 0 \mu \mathrm{m}$ in length, occurring singly and sometimes in pairs. Colonies are circular, smooth, pulvinate, entire, opaque, white and viscous when grow on sucrose agar plates. Catalase and urease are produced, but oxidase, lipase and indole are not. Growth occurs at $10{ }^{\circ} \mathrm{C}$ but gas is not produced from lactose at $45^{\circ} \mathrm{C}$. The Voges-Proskauer test is positive and the methyl red reaction is negative. Nitrate is not reduced. Gelatin, starch, cellulose and casein are not fermented. There are no special growth-factor requirements. Citrate and glucose can be used as a sole carbon source. Fails to produce $\mathrm{H}_{2} \mathrm{~S}$. Acids and gas are produced from glucose, sucrose, lactose, trehalulose, maltose, fructose, mannitol, glycerol, inositol, mannose, galactose and sorbitol. Does not utilize palatinose or L-sorbose as sole carbon sources. The optimum temperature is $30^{\circ} \mathrm{C}$ and the optimum $\mathrm{pH}$ is $7 \cdot 0$. The $\mathrm{G}+\mathrm{C}$ content of the DNA is $56 \cdot 4 \mathrm{~mol} \%$.

The type strain is $\operatorname{LX}^{\mathrm{T}}\left(=\mathrm{DSM} 16265^{\mathrm{T}}=\mathrm{JCM} 12419^{\mathrm{T}}\right)$.

\section{Acknowledgements}

This study was funded by Scientific Funding of Liaoning and partially by the Dalian Authority of Science and Technology.

\section{References}

Bagley, S. T., Seidler, R. J. \& Brenner, D. J. (1981). Klebsiella planticola sp. nov.: a new species of Enterobacteriaceae found primarily in nonclinical environments. Curr Microbiol 6, 105-109.

Carter, J. S., Bowden, F. J., Bastian, I., Myers, G. M., Sriprakash, K. S. \& Kemp, D. J. (1999). Phylogenetic evidence for reclassification of Calymmatobacterium granulomatis as Klebsiella granulomatis comb. nov. Int J Syst Bacteriol 49, 1695-1700.

Cheetham, P. S. J., Imber, C. E. \& Isherwood, J. (1982). The formation of isomaltulose by immobilized Erwinia rhapontici. Nature 299, 628-631.

Cole, J. R., Chai, B., Marsh, T. L. \& 8 other authors (2003). The Ribosomal Database Project (RDP-II): previewing a new autoaligner that allows regular updates and the new prokaryotic taxonomy. Nucleic Acids Res 31, 442-443.

Doetsch, R. N. (1981). Determinative methods of light microscopy. In Manual of Methods for General Bacteriology, pp. 21-33. Edited by P. Gerhard, R. G. E. Murray, R. N. Costilow, E. W. Nester, W. A. 
Wood, N. R. Krieg \& G. B. Phillips. Washington, DC: American Society for Microbiology.

Drancourt, M., Bollet, C., Carta, A. \& Rousselier, P. (2001). Phylogenetic analyses of Klebsiella species delineate Klebsiella and Raoultella gen. nov., with description of Raoultella ornithinolytica comb. nov., Raoultella terrigena comb. nov. and Raoultella planticola comb. nov. Int J Syst Evol Microbiol 51, 925-932.

Etchebehere, C., Pavan, M. E., Zorzópulos, J., Soubes, M. \& Muxí, L. (1998). Coprothermobacter platensis sp. nov., a new anaerobic proteolytic thermophilic bacterium isolated from an anaerobic mesophilic sludge. Int J Syst Bacteriol 48, 1297-1304.

Felsenstein, J. (1995). PHYLIP-phylogeny inference package (version 3.57c). Seattle: University of Washington.

Marmur, J. \& Doty, P. (1962). Determination of the base composition of deoxyribonucleic acid from its thermal denaturing temperature. J Mol Biol 5, 109-118.

McAllister, M., Kelly, C. T., Doyle, E. \& Fogarty, W. M. (1990). The isomaltulose synthesizing enzyme of Serratia plymuthica. Biotechnol Lett 12, 667-672.

Miller, G. L. (1959). Use of dinitrosalicylic acid reagent for the determination of reducing sugars. Anal Chem 31, 426-428.

Miyata, Y., Sugitani, T., Tsuyuki, K., Ebashi, T. \& Nakajima, Y. (1992). Isolation and characterization of Pseudomonas mesoacidophila producing trehalulose. Biosci Biotechnol Biochem 56, 1680-1681.

Mollet, C., Drancourt, M. \& Raoult, D. (1997). rpoB sequence analysis as a novel basis for bacterial identification. Mol Microbiol 26, 1005-1011.

Ørskov, I. (1984). Genus V. Klebsiella Trevisan 1885, $105^{\mathrm{AL}}$. In Bergey's Manual of Systematic Bacteriology, vol. 1, pp. 461-465. Edited by N. R. Krieg \& J. G. Holt. Baltimore: Williams \& Wilkins.

Richens, J. (1991). The diagnosis and treatment of donovanosis (granuloma inguinale). Genitourin Med 67, 441-452.

Sakazaki, R., Tamura, K., Kosako, Y. \& Yoshizaki, E. (1989). Klebsiella ornithinolytica sp. nov., formerly known as ornithinepositive Klebsiella oxytoca. Curr Microbiol 18, 201-206.
Schwimmer, S. \& Bevenue, A. (1956). Reagent for differentiation of 1,4- and 1,6-linked glucosaccharides. Science 123, 543-544.

Smibert, R. M. \& Krieg, N. R. (1994). Phenotypic characterization. In Methods for General and Molecular Microbiology, pp. 607-654. Edited by P. Gerhardt, R. G. E. Murray, W. A. Wood \& N. R. Krieg. Washington, DC: American Society for Microbiology.

Stodola, F. H., Sharpe, E. S. \& Koepsell, H. J. (1956). The preparation, properties and structure of the disaccharide leucrose. J Am Chem Soc 78, 2514-2518.

Takazoe, I., Ohta, K., Kadomura, Y. \& Nakajima, Y. (1982). Inhibitory mechanism of isomaltulose for insoluble glucan synthesis by Streptococus mutans. J Dent Res 61, 340.

Thompson, J. D., Gibson, T. J., Plewniak, F., Jeanmougin, F. \& Higgins, D. G. (1997). The CLUSTAL_X windows interface: flexible strategies for multiple sequence alignment aided by quality analysis tools. Nucleic Acids Res 25, 4876-4882.

Topitsoglou, V., Sasaki, N., Takazoe, I. \& Frostell, G. (1984). Effect of frequent rinses with isomaltulose (palatinose) solution on acid production in human dental plaque. Caries Res 18, 47-51.

Tsuyuki, K., Sugitani, T., Miyata, Y., Ebashi, T. \& Nakajima, Y. (1992). Isolation and characterization of isomaltulose- and trehalulose-producing bacteria from Thailand soil. J Gen Appl Microbiol 38, 483-490.

Weidenhageen, R. \& Lorenz, S. (1957). Transformation of sucrose to palatinose (6-[ $\alpha$-glucopyranosyl]-fructofuranose) by a new bacterium. Z Zuckerind 7, 533-534 (in German).

Wilson, K. (1990). Preparation of genomic DNA from bacteria: miniprep of bacterial genomic DNA. In Current Protocols in Molecular Biology, vol. 1, pp. 2.4.1-2.4.2. Edited by F. M. Ausubel, R. Brent, R. E. Kingston, D. D. Moore, J. G. Seidman, J. A. Smith \& K. Struhl. New York: Wiley.

Yoon, J.-H., Kang, S.-S., Mheen, T.-I. \& 7 other authors (2001). Lactobacillus kimchii sp. nov., a new species from kimchi. Int J Syst Evol Microbiol 50, 1789-1795.

Ziemke, F., Höfle, M. G., Lalucat, J. \& Rosselló-Mora, R. (1998). Reclassification of Shewanella putrefaciens Owen's genomic group II as Shewanella baltica sp. nov. Int J Syst Bacteriol 48, 179-186. 